\title{
Estimativas das Distâncias para Disposição de Resíduos Sólidos Urbanos no Estado de São Paulo
}

Distance Estimations for Municipal Solid Waste Disposal in the São Paulo

State

Laryssa Alvarenga de Morais ${ }^{1}$

Victor Fernandez Nascimento 2,3

Laurindo Antonio Guasselli ${ }^{2}$

Jean Pierre Henry Balbaud Ometto ${ }^{3}$

Recebido em maio de 2019. Aprovado em novembro de 2019.

\begin{abstract}
RESUMO
Os resíduos sólidos urbanos (RSU) representam uma das grandes preocupações ambientais, sociais e econômicas contemporâneas. No Brasil, 78,3 milhões de toneladas de RSU foram gerados no ano de 2016. Apenas no estado de São Paulo, neste mesmo ano, foram gerados cerca de 14,6 milhões de toneladas, cerca de $19 \%$ do que foi gerado no país. No gerenciamento dos RSU a coleta e o transporte são as etapas que mais impactam o orçamento financeiro, em média são gastos de 40 a $70 \%$ dos recursos nessas etapas. Além disso, o transporte dos RSU também impacta o meio ambiente através das emissões de gases de efeito estufa provenientes dos caminhões. O objetivo deste trabalho foi estimar e analisar espacialmente utilizando Sistemas de Informação Geográficas (SIG) as distâncias percorridas pelos caminhões de coleta de RSU desde os centros urbanos até os locais de disposição final dos RSU em escala regional para os municípios do estado de São Paulo. Os resultados demonstraram que para transportar os RSU dos municípios paulistas, durante o ano de 2016, foram percorridos aproximadamente 91 milhões de quilômetros. Este valor é suficiente para dar mais de 2.293 voltas no planeta Terra, e consequentemente contribui para os altos custos ambientais e econômicos desta etapa do gerenciamento dos RSU.
\end{abstract}

PALAVRAS-CHAVE: Lixo. Sistema de Informação Geográfica. Roteirização.

\footnotetext{
${ }^{1}$ Universidade Estadual Paulista (UNESP, Campus de São José dos Campos). E-mail: laryssa.morais@unesp.com

${ }^{2}$ Universidade Federal do Rio Grande do Sul (UFRGS), Programa de Pós-graduação em Sensoriamento Remoto (PPGSR), Laboratório de Geoprocessamento e Análise Ambiental (LAGAM). E-mails: victorfnasciento@gmail.com; laurindo.guasselli@ufrgs.br

${ }^{3}$ Instituto Nacional de Pesquisas Espaciais (INPE), Centro de Ciência do Sistema Terrestre (CCST)

E-mail: jean.ometto@inpe.br
} 


\begin{abstract}
Municipal solid waste (MSW) is one of the major environmental, social and economic concerns. In Brazil, 78.3 MSW million tons were generated in the year 2016. In the São Paulo state, about 14.6 million tons were generated, around $19 \%$ of what was generated in the whole country. In the MSW management, collection and transport are the stages that most affect the financial budget, on average 40 to $70 \%$ of the economic resources are spent in these phases. In addition, this also influences the environment through greenhouse gas emissions caused by MSW trucks. This study objective was to estimate and spatially analyze using Geographic Information Systems (GIS) the distances traveled by MSW collection trucks from urban centers to final MSW disposal sites on a regional scale for all municipalities in the state of São Paulo during the year of 2016. The results showed that to transport MSW in the São Paulo state the trucks had traveled approximately 91 million kilometers. This distance is sufficient to give more than 2,293 laps on planet Earth and consequently contributes to the high environmental and economic costs of this MSW management stage.
\end{abstract}

KEYWORDS: Waste. Geographic Information System. Route.

$$
* * *
$$

\title{
1 Introdução
}

Os resíduos sólidos urbanos (RSU), representam uma das grandes preocupações ambientais contemporâneas no Brasil (NASCIMENTO et al., 2019). Provenientes das atividades domiciliares e da limpeza de logradouros públicos, se não forem adequadamente geridos, podem provocar sérios danos ao ambiente e à sociedade. Municípios com gestão ineficiente de RSU sofrem com poluição atmosférica decorrente de material particulado, odores e gases nocivos; poluição dos corpos hídricos resultante do chorume de "lixões" e do lançamento direto destes resíduos no ambiente; degradação e contaminação do solo; desvalorização imobiliária das áreas próximas aos locais de disposição de resíduos; e a proliferação de doenças através de vetores associados (ANDRADE e FERREIRA, 2011).

As influências e interferências de ordem política, técnica e cultural, decorrentes de modelo capitalista hegemônico e de processo crescente de globalização contribuem para maximizar a geração de resíduos e torna a gestão de RSU ainda mais problemática (ANDRADE e FERREIRA, 2011). Segundo a WWN (2010), os novos padrões de consumo, entre outros fatores, 
estão provocando impactos ambientais irreversíveis. A amplitude dos impactos dos RSU pode ser depreendida a partir dos volumes de geração, associados ao nível de eficácia da sua gestão e aos malefícios que isso pode acarretar (GODECKE et al, 2012).

No Brasil, de acordo com a Associação Brasileira de Limpeza Pública e Resíduos Especiais (ABRELPE), a geração de RSU aumentou 25\% de 2012 a 2016. No ano de 2016, os números referentes à geração de RSU revelam um total anual de quase 78,3 milhões de toneladas no país (ABRELPE, 2016). Apenas no estado de São Paulo, segundo a Companhia Ambiental do Estado de São Paulo (CETESB), foram gerados respectivamente nos anos de 2012 e 2017, 9.672.026 toneladas/ano e 14.560.215 toneladas/ano, totalizando um aumento de aproximadamente 51\% neste período (CETESB, 2012; 2017).

O elevado volume de RSU gerado pela sociedade merece um tratamento especial das gestões municipais e a implementação de estratégias de curto, médio e longo prazo que permitam controlar e gerenciar, principalmente, os sistemas de serviços de transporte, coleta e disposição final dos resíduos (GONZÁLEZ e LEAL, 2016). Uma vez que os custos associados a estas etapas representam, em termos de orçamentais, 40\% a 70\% do custo total de um sistema de gestão de RSU (MARTINHO e GONÇALVES, 2000).

O montante de RSU coletado e transportado no Brasil em 2017 foi de 71,6 milhões de toneladas, um índice de cobertura de coleta de 91,2\% para o país. O que acarretou em um custo de 10.145 milhões de reais por ano, na região Sudeste, a qual apresenta o maior percentual de cobertura dos serviços de coleta do país. Os recursos gastos com tais operações contabilizaram um valor de aproximadamente 5.343 milhões de reais (ABRELPE, 2017).

Moustafa et al. (2013), ressaltam que os serviços de coleta e transporte são áreas da gestão de RSU que vem ganhando enormes benefícios com a utilização de Sistemas de Informação Geográficas (SIG). Segundo Gallardo et al. (2015), os SIG são utilizados como apoio no planejamento de coleta e transporte de RSU, pois são extremamente úteis em trabalhos de análise e tratamento de dados espaciais. 
Neste sentido, uma das aplicações dos SIG, que se destaca neste estudo, são as funções de roteirização. O principal benefício é a utilização de mapas digitais editados em ambiente SIG, que servem para simplificar o processo de tomada de decisão na seleção das melhores alternativas econômicas e logísticas das rotas de coleta e transporte de RSU.

Segundo Malakahmad et al. (2014), em qualquer operação de coleta e transporte de resíduos é importante considerar as rotas dos veículos. E a escolha de rotas eficientes que minimizem a distância, o custo e o tempo destas operações é um objetivo a ser alcançado (CHANG, 1997). Logo, a utilização da tecnologia SIG é amplamente aceita na comunidade de gestão de RSU, pois a tomada de decisão eficaz requer a implementação de técnicas de roteirização de veículos (TAVARES et al., 2009).

Este trabalho teve como objetivo identificar utilizando análises geoespaciais através de SIG a roteirização linear e por vias de transporte utilizadas pelos caminhões de coleta de RSU para posteriormente se estimar as distâncias percorridas para se dispor estes resíduos desde os centros urbanos até os locais de disposição final em escala regional considerando todos os municípios do estado de São Paulo.

\section{Metodologia}

Para alcançar os objetivos propostos, foram realizadas e descritas as seguintes etapas, fluxograma da (Figura 1). 
Figura 1 - Fluxograma das etapas da pesquisa

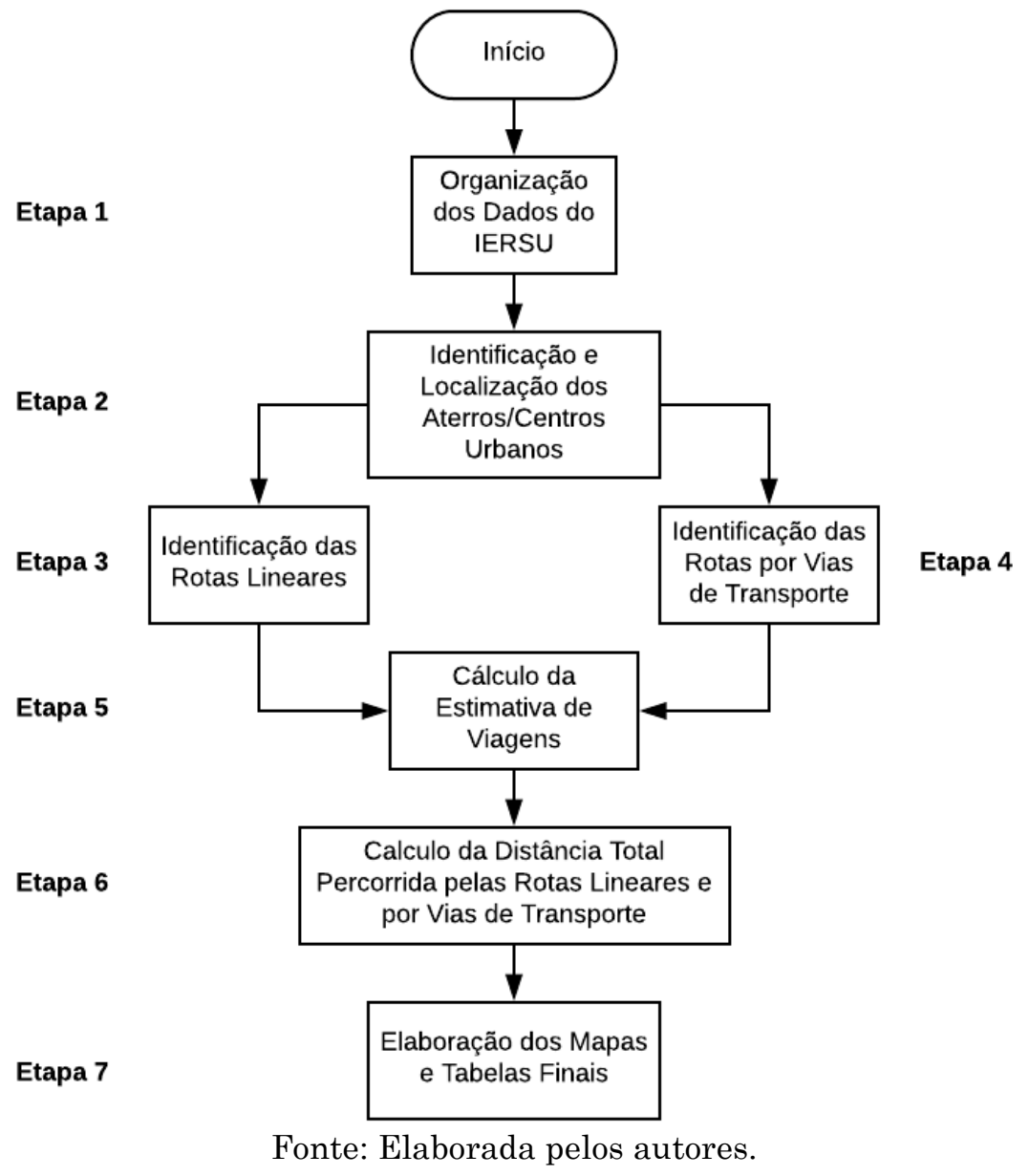

Na primeira etapa foi realizado o levantamento dos dados com base no Inventário Estadual de Resíduos Sólidos Urbanos (IERSU) divulgado pela (CETESB, 2017). Foram extraídas informações a respeito das condições básicas dos aterros sanitários do estado de São Paulo para o ano de 2016 como: (i)localização, (ii) enquadramento dos aterros quanto ao Índice de Qualidade de Resíduos (IQR), (iii) quantidade de RSU dispostos em cada aterro em tonelada por dia, e (iv) quantidade de RSU gerada individualmente pelos 645 municípios. Também foram identificados quais municípios dispõem os RSU em aterros localizados em outra cidade do estado, utilizando aterros consorciados, ou até mesmo fora do estado de São Paulo. Todos estes dados foram organizados em tabelas utilizando o software Excel.

$\mathrm{Na}$ segunda etapa, fazendo uso da plataforma ArcGis 10.5, com as extensões ArcMap e Arctoolbox, foram transferidos os dados tabulares para 
arquivos em formato shapefile. Estes dados foram elaborados com auxílio das informações disponíveis nas planilhas do IQR, contidas no Mapa de Destinação de Resíduos Urbanos, divulgado pela CETESB, principalmente a de localização dos aterros sanitários (latitude e longitude). Os aterros sem localização geográfica, foram identificados visualmente por imagens de satélites Landsat, obtendo-se os pontos georreferenciados dos aterros. Esse procedimento também foi executado para o shapefile da cobertura urbanizada do estado de São Paulo, com auxílio de imagens de satélite foram identificados pontos referentes aos centros urbanos dos municípios. O sistema de coordenadas adotado foi o SIRGAS 2000 (Zona UTM 22 e 23 S).

$\mathrm{Na}$ terceira e quarta etapa, as rotas foram criadas, sendo representadas por uma "linha" interligando os pontos georreferenciados definidos como centro dos municípios e o local de disposição final dos RSU. Foram elaborados dois tipos de rotas, as lineares e as por vias de transporte. Na etapa 3, para a confecção das rotas lineares, criou-se apenas uma linha reta interligando os centros urbanos das cidades e os seus respectivos locais de disposição final de RSU.

O mesmo procedimento foi adotado para elaboração das rotas por vias de transporte, na quarta etapa. Entretanto, seguiu-se estradas para a identificação do percurso, e a roteirização utilizou imagens de satélites Landsat do ano de 2016, associada com os dados gratuitos de ruas do Open Street Maps obtidos em abril de 2018.

Estas bases de dados serviram como base para a obtenção das vias utilizadas no tráfego dos veículos de transporte dos RSU. Como critério para escolha das vias e confeç̧ão das rotas optou-se sempre por rodovias e estradas de grande porte e de preferência pavimentadas.

$\mathrm{Na}$ quinta etapa os dados da quantidade de RSU (ton/ano) geradas por cada município, obtidos por meio do IERSU, foram agrupados aos arquivos vetoriais, assim, foi estimado e calculado o número de viagens realizadas pelos veículos coletores de resíduos. De acordo com a NBR 13463, os veículos de coleta de RSU podem ser do tipo caçamba simples e coletor compactador 
(ABNT, 1995), e cada tipo é empregado de acordo com a quantidade de resíduos, forma de acondicionamento e condições de acesso ao ponto de coleta (VILHENA, 2010). No Brasil, atualmente, os veículos compactadores de carregamento traseiro são os mais utilizados por serem mais viáveis economicamente (SPIGOLON, 2015).

A capacidade do peso de carga destes caminhões é de 12 toneladas de acordo com o Manual de Gerenciamento Integrado de Resíduos Sólidos Instituto Brasileiro de Administração Municipal (ZVEIBIL, 2001). O valor utilizado para estabelecer a capacidade de carga neste estudo foi de $80 \%$ do peso estipulado de 12 ton, ou seja, 9,6 ton, uma vez que não são em todas as viagens que o caminhão carrega o seu volume máximo permitido. Em contrapartida, em dias chuvosos, o peso do lixo aumenta cerca de $20 \%$, dessa forma, a capacidade de peso máximo de carga é atingida antes de completar o volume máximo de carregamento do veículo (ZVEIBIL, 2001). Vale ressaltar que os valores calculados, referentes ao número de viagens, foram arredondados para cima, quando possuíam casas decimais diferentes de zero.

$\mathrm{Na}$ sexta etapa foram calculadas as distâncias referentes as rotas lineares e por vias de transporte, por intermédio da ferramenta Calculate Geometry do ArcGis e obteve-se o valor correspondente a distância total percorrida pelos veículos transportadores de resíduos.

$\mathrm{Na}$ sétima e na última etapa foram elaborados produtos cartográficos temáticos e tabelas, referentes ao número de viagens realizadas pelos veículos coletores de RSU e as distâncias obtidas por meio das rotas por vias e das rotas lineares. Para a primeira análise, considerou-se apenas as distâncias percorridas pelos veículos coletores de resíduos e somente o percurso de ida. Para a segunda análise, foram realizadas e calculadas as distâncias percorridas levando em consideração tanto o percurso de ida e volta como o número de viagens necessárias para dispor os RSU nos aterros. 


\section{Resultados e Discussão}

A Tabela 1 exibe informações sobre os aterros sanitários em atividade em 2016 no estado de São Paulo. Fazem referência ao número de municípios que dispõem nas três classes de aterros abordadas neste estudo (aterros individuais, consorciados e localizados fora do estado), além da quantidade de RSU disposto em cada uma das três classes e o valor médio do IQR.

Tabela 1 - Situação da disposição dos RSU no estado de São Paulo para o ano de 2016

\begin{tabular}{c|c|c|c|c}
\hline & $\mathbf{N}^{\mathbf{0}}$ & $\begin{array}{c}\mathbf{N}^{\mathbf{0}} \text { de } \\
\text { Municípios }\end{array}$ & $\begin{array}{c}\text { Quantidade de } \\
\text { RSU disposto } \\
\text { (ton) }\end{array}$ & IQR médio \\
\hline $\begin{array}{c}\text { Aterros } \\
\text { individuais }\end{array}$ & 366 & 366 & $6.489 .311,76$ & 7,81 \\
\hline $\begin{array}{c}\text { Aterros } \\
\text { consorciados }\end{array}$ & 35 & 273 & $8.156 .335,62$ & 9,36 \\
\hline $\begin{array}{c}\text { Aterros fora } \\
\text { do estado* }\end{array}$ & 3 & 6 & $23.387,40$ & - \\
\hline Totais & 401 & 645 & $14.669 .034,78$ & 8,49 \\
\hline
\end{tabular}

*Aterros que se localizam fora do território do estado de São Paulo utilizados por municípios paulistas

Fonte: Elaborada pelos autores.

Ao todo foram 401 aterros utilizados entre os 645 municípios do estado de São Paulo. Pouco mais da metade, 366 dos municípios possuem aterros no seu território e cerca de 273 deles utilizam de forma compartilhada 35 aterros consorciados.

Três aterros estão localizados fora do estado de São Paulo nos municípios de Barra Mansa - RJ, Rio Negrinho - SC e Uberaba - MG, e servem como destino final dos resíduos sólidos gerados por seis municípios paulistas (Arapeí, Bananal, Iguarapava, Ituverara, Ribeira e São José do Barreiro) os quais não foram levados em consideração neste estudo. Vale ressaltar que o total de resíduos dispostos por estes seis municípios se somados não ultrapassam $0,1 \%$ de todo o RSU disposto no estado de São Paulo.

Ao todo, foram elaboradas 644 rotas, desconsiderando os municípios que dispõem fora do estado de São Paulo e considerando que cinco municípios, Arujá, Marília, São Paulo, Suzano e Piracicaba dispuseram seus RSU em dois 
aterros diferentes dentro do estado, ou seja, possuem mais de uma rota para a disposição final de seus resíduos.

O total de RSU disposto nos aterros individuais e consorciados de São Paulo, em 2016, é de aproximadamente 14.6 milhões de toneladas por ano, tornando São Paulo o maior estado gerador de resíduos da América do Sul. Isto demonstra a elevada quantidade de RSU destinados aos aterros sanitários e que consequentemente precisam ser transportados das áreas urbanas até os locais de disposição.

De acordo com o Instituto Brasileiro de Geografia e Estatística (IBGE, 2008), em dez anos a porcentagem de resíduos dispostos nos aterros, de todo país, subiu de $17 \%$ para $27 \%$. Isso porque a destinação final dos resíduos sólidos em aterros sanitários confere menor risco à população local e ao meio ambiente, quando estes aterros são construídos e operados de acordo com a normas brasileiras.

Em relação ao enquadramento dos aterros no estado de São Paulo quanto ao Índice de Qualidade de Resíduos (IQR), tanto os aterros individuais quanto os consorciados possuem valores de IQR médio acima dos valores utilizados como parâmetro pela CETESB, que no caso é de 7,1 a 10. Contudo, o valor de IQR médio dos aterros consorciados é muito mais elevado em comparação aos individuais, atingindo quase o valor máximo da escala de referência. Este fato pode estar atrelado a múltiplos fatores, entre eles a ação da Política Nacional de Resíduos Sólidos (PNRS).

O PNRS além de fortalecer os princípios da gestão integrada e sustentável de resíduos, propõe medidas de incentivo à formação de consórcios públicos para a gestão regionalizada com vistas a ampliar a capacidade de gestão das administrações municipais, por meio de ganhos de escala e redução de custos no caso de compartilhamento de sistemas de coleta, tratamento e destinação de resíduos sólidos (BRASIL, 2010). 
A partir das rotas foi possível estimar as distâncias entre os centros urbanos dos municípios até os locais de disposição final dos RSU. O resultado total foi de aproximadamente $11.280 \mathrm{~km}$, para as rotas lineares (Tabela $2 \mathrm{e}$ Figura ), e $17.641 \mathrm{~km}$, para as rotas por vias de transporte (Tabela 3 e Figura 3).

Tabela 2 - Distâncias obtidas através de rotas lineares

\begin{tabular}{c|c|c}
\hline \multicolumn{3}{c}{ Rotas Lineares } \\
\hline Classes de Distância & $\mathbf{N}^{\circ}$ de Municípios & Distância Total (km) \\
\hline$<1 \mathrm{~km}$ & 15 & 9,81 \\
\hline $1-3 \mathrm{~km}$ & 152 & 322,89 \\
\hline $3-5 \mathrm{~km}$ & 126 & 488,87 \\
\hline $5-10 \mathrm{~km}$ & 105 & 707,42 \\
\hline $10-20 \mathrm{~km}$ & 76 & $1.045,26$ \\
\hline $20-50 \mathrm{~km}$ & 103 & $3.416,69$ \\
\hline$>50 \mathrm{~km}$ & 67 & $5.289,84$ \\
\hline
\end{tabular}

A análise da Tabela 2, mostra um maior número de municípios (24\% do total) em que a distância do centro urbano até o aterro se encontra na classe de 1 a $3 \mathrm{~km}$. Este intervalo pode ser considerado curto e representa uma vantagem econômica e ambiental associada a redução de custo, tempo e impacto gerado pelo tráfego destes veículos. Do total, 67 municípios possuem distâncias maiores que $50 \mathrm{~km}$, totalizando um valor de aproximadamente $5.290 \mathrm{~km}$. Todos estes municípios dispuseram seus resíduos em aterros consorciados, que por sua vez se localizam mais distantes dos seus respectivos centros urbanos. Os outros municípios, estão bem distribuídos em relação as outras classes de distâncias. Com exceção da classe de distâncias menores que $1 \mathrm{~km}$, com apenas 15 municípios.

O fator da proximidade dos aterros dos centros urbanos ainda que diminua os custos com transporte, apresenta um efeito social negativo. Esta proximidade causa impactos visuais, poluição olfativa, proliferação de vetores e presença de microrganismos patogênicos, liberação de gases tóxicos, 
asfixiantes e explosivos que se acumulam no subsolo ou são lançados na atmosfera comprometendo a qualidade do ar e, ainda, a contaminação do solo e das águas superficiais e subterrâneas devido a decomposição da matéria orgânica, que resulta em chorume (GOUVEIA, 2012).

Causa o efeito conhecido na literatura internacional como a sigla "NIMBY" (Not in my back Yard), na qual o indivíduo não deseja que exista um aterro sanitário próximo de sua residência, tendo em mente que todas essas ocorrências não se restringem apenas a área de disposição final dos resíduos, mas estendem-se além desta, afetando toda a população inserida nesse meio (DEAR, 2007).

A Figura 2 ilustra as rotas lineares, onde se destacam os aterros consorciados que recebem resíduos sólidos de vários municípios, como é o caso do aterro de Piratininga no centro do estado, o aterro de Catanduva, na Região Norte do estado, e o aterro de Paulínia na Região Metropolitana de Campinas, tais aterros receberam resíduos respectivamente de 23,23 , e 33 municípios.

Em relação a quantidade de resíduos dispostos, o aterro de Paulínia, está entre os três que mais receberam RSU no estado em 2016 cerca de 1,1 milhão de toneladas de resíduos, perdendo apenas para os aterros de São Paulo e Caieiras, ambos localizados na Região Metropolitana de São Paulo, que receberam 2,7 e 2,1 milhões de toneladas de RSU, respectivamente. 
Figura 2 - Distâncias obtidas através de rotas lineares

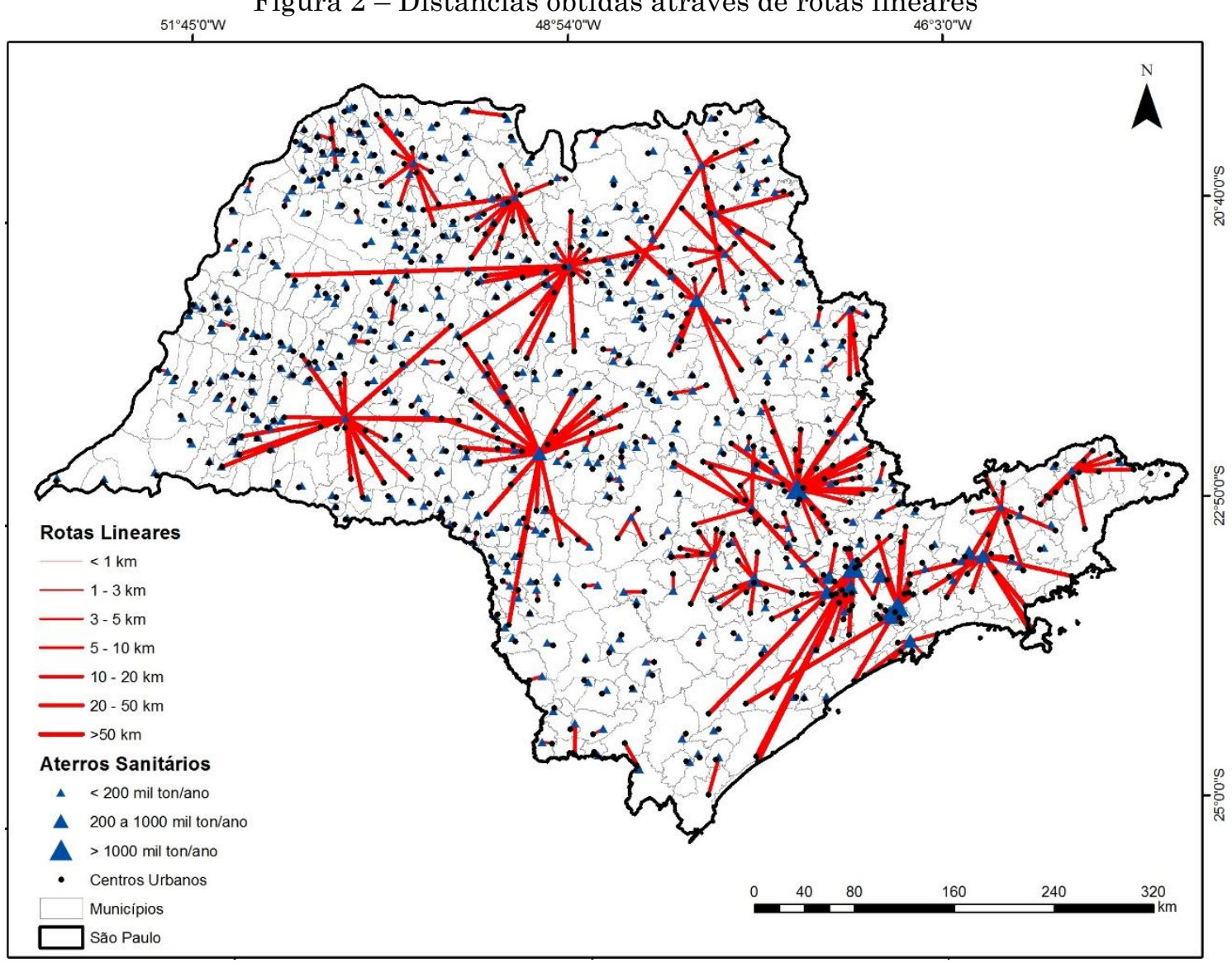

Fonte: Elaborada pelos autores.

Para comparação, os resultados foram gerados para as rotas por vias de transporte, tanto a tabela quanto a produção cartográfica (Figura 3). Na Tabela 3, as classes de distâncias percorridas dos centros urbanos dos municípios até os aterros se mantiveram as mesmas das utilizadas nas rotas lineares para se comparar as diferenças entre rotas lineares e por vias de transporte.

Tabela 3 - Distâncias obtidas através de rotas por vias.

\begin{tabular}{c|c|c}
\hline \multicolumn{3}{|c}{ Rotas por Vias } \\
\hline Classes de Distância & $\mathbf{N}^{\circ}$ de Municípios & Distância Total (km) \\
\hline$<1 \mathrm{~km}$ & 9 & 7,02 \\
\hline $1-3 \mathrm{~km}$ & 96 & 211,88 \\
\hline $3-5 \mathrm{~km}$ & 127 & 498,12 \\
\hline $5-10 \mathrm{~km}$ & 123 & 851,94 \\
\hline $10-20 \mathrm{~km}$ & 74 & $1.029,49$ \\
\hline $20-50 \mathrm{~km}$ & 96 & $3.250,52$ \\
\hline$>50 \mathrm{~km}$ & 119 & $11.792,07$ \\
\hline
\end{tabular}

Fonte: Elaborada pelos autores. 
A análise da Figura 3 mostra que o intervalo de distância de 3 a $5 \mathrm{~km}$, abrange o maior número de municípios, dos 639 municípios em análise 20\% fazem parte dessa classe. $\mathrm{O}$ intervalo de 1 a $3 \mathrm{~km}$, que para as rotas lineares contemplava o maior número de municípios, nas rotas por vias é o quarto maior, empatado com o intervalo de 20 a $50 \mathrm{~km}$.

Além disso, merece destaque as distâncias maiores que $50 \mathrm{~km}$, nas rotas lineares esse intervalo reunia 67 municípios, no entanto, para as rotas por vias de transporte, cerca de 119 municípios estão agrupados nesta classe. Essa discrepância no número de municípios se deve ao fato de que no momento de criação das rotas por vias optou-se por rodovias de grande porte e de preferência pavimentadas. Assim, as distâncias percorridas por muitos municípios aumentaram bastante quando comparadas com as distâncias lineares, uma vez que esta última corresponde a menor distância existente entre o ponto georreferenciado do centro urbano do município até o aterro sanitário. 
Figura 3 - Distâncias obtidas através de rotas por vias ${ }_{40^{\circ} 5^{\circ} 5^{\circ} 0^{\circ} \mathrm{O} w \mathrm{w}}$

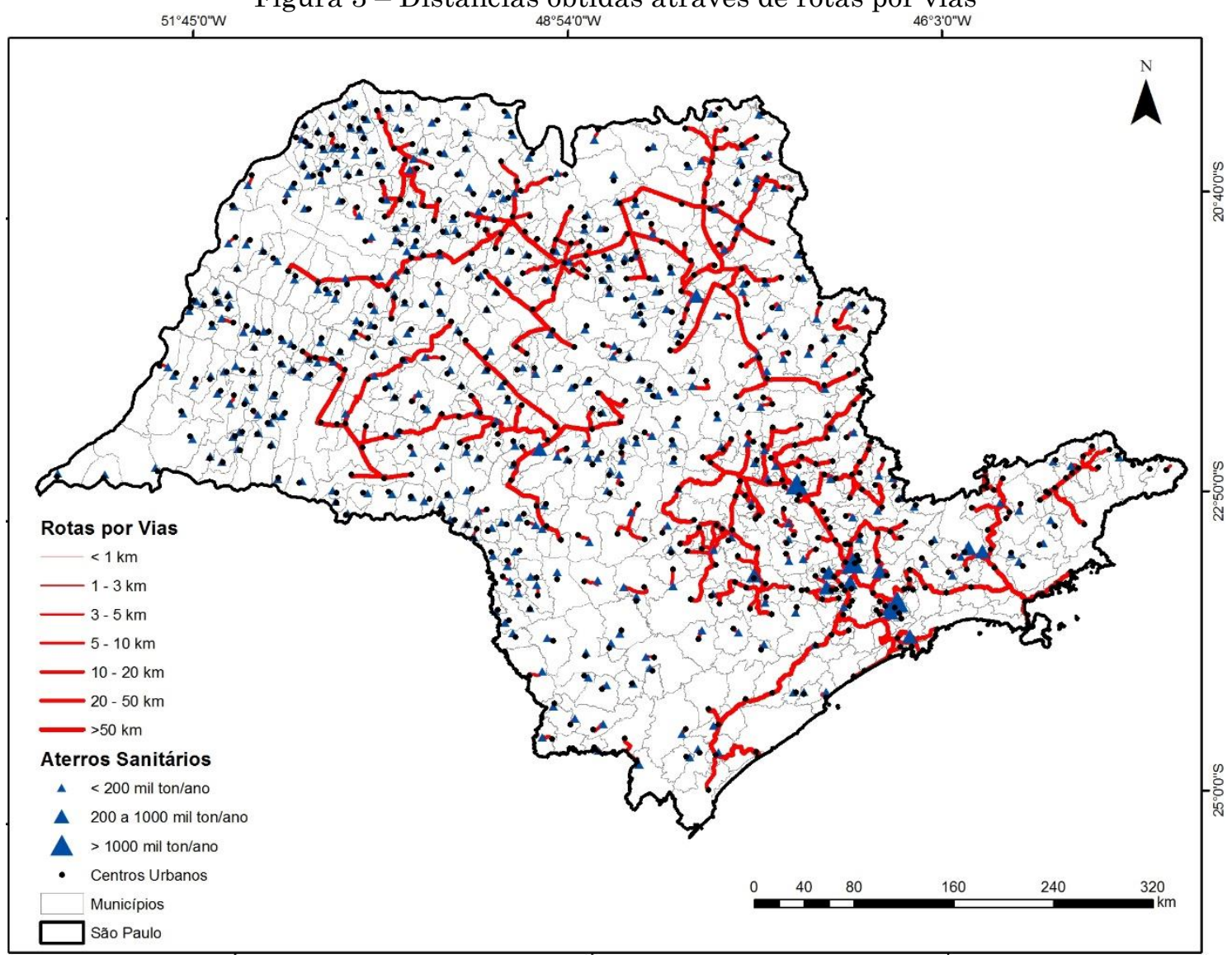

Fonte: Elaborada pelos autores.

\subsection{Número de Viagens}

O número de viagens necessárias para um veículo de RSU transportar os resíduos do centro urbano até o aterro sanitário está atrelado a capacidade de carga do veículo juntamente com a quantidade de RSU gerado pelo município. Para estimar o número de viagens realizadas foi considerado todo o resíduo gerado no período de um ano. Algumas classes referentes aos números de viagens, e a quantidade de municípios que as compõem, foram definas e estão apresentadas na Tabela 3. 
Tabela 3 - Estimativa do número de viagens realizadas de pelos veículos de RSU

\begin{tabular}{c|c}
\hline $\mathbf{N}^{\mathbf{o}}$ de Viagens & $\mathbf{N}^{\mathbf{o}}$ de Municípios \\
\hline$<500$ & 398 \\
\hline $500-1.000$ & 68 \\
\hline $1.000-10.000$ & 149 \\
\hline $10.000-50.000$ & 22 \\
\hline$>50.000$ & 2 \\
\hline
\end{tabular}

Fonte: Elaborada pelos autores.

Aproximadamente $62 \%$ dos 639 municípios fizeram menos de 500 viagens. Estes munícipios geram uma quantidade de RSU relativamente baixa em comparação aos demais, isso se deve ao fato de que $42 \%$ dos municípios paulistas possuem menos do que 10 mil habitantes e consequentemente não geram grandes quantidades de RSU.

A classe com intervalo entre 1.000 e 10.000 viagens, abrange $23 \%$ de todos os municípios, sendo a segunda mais assídua. $\mathrm{E}$ apenas dois municípios, São Paulo e Guarulhos, realizaram mais de 50.000 viagens para dispor seus resíduos. Esses municípios são os maiores geradores de resíduos do estado, com uma geração de aproximadamente 2.750 .753 e 538.312 toneladas de RSU/ano, respectivamente.

\subsection{Estimativas das Distâncias Totais}

Para obter as distâncias totais percorrida pelos veículos coletores de RSU, foi considerado o valor referente ao percurso de ida e volta multiplicado pelo número de viagens necessário para que todos os resíduos gerados nos municípios fossem dispostos nos aterros. O valor total correspondente a somatória de todas as distâncias percorridas por tais veículos é de aproximadamente $64.901 .922 \mathrm{~km}$, para as rotas lineares (Tabela 5), e de $91.930 .153 \mathrm{~km}$, para as rotas por vias de transporte (Tabela 6).

De acordo com os dados da Tabela 5, cerca de 53\% dos municípios percorrem de 1.000 a $50.000 \mathrm{~km}$ para disporem seus resíduos e a distância total percorrida por estes 336 municípios foi de aproximadamente 3.7 milhões de $\mathrm{km}$. 
O intervalo de valores inferiores a $1.000 \mathrm{~km}$ foi o segundo em número de municípios, com cerca de $26 \%$ do total, sendo que a maior parte dos municípios fazem uso dos aterros existentes em seus limites territoriais. As classes de 50.000 a $100.000 \mathrm{~km}$ e de 100.000 a $500.000 \mathrm{~km}$, abrangem respectivamente $8 \%$ e $10 \%$ dos municípios, o que representa uma distribuição relativamente uniforme entre ambas as classes.

Por último, vale salientar que apenas 22 municípios estão classificados em distâncias percorridas superiores a 500.000 km, porém são responsáveis pela maior distância percorrida total com um valor próximo a 42.6 milhões de $\mathrm{km}$.

Tabela 5 - Distâncias percorridas pelos veículos de RSU através de rotas lineares

\begin{tabular}{c|c|c}
\hline \multicolumn{3}{c}{ Rotas Lineares } \\
\hline $\begin{array}{c}\text { Distância Percorrida } \\
\left.\text { (Ida/Volta) } \mathbf{x ~ n}^{\mathbf{0}} \text { de viagens } \mathbf{( k m}\right)\end{array}$ & $\mathbf{N}^{\circ}$ de Municípios & $\begin{array}{c}\text { Distância Total } \\
\mathbf{( k m )}\end{array}$ \\
\hline$<1.000$ & 168 & $72.342,30$ \\
\hline $1.000-50.000$ & 336 & $3.712 .908,04$ \\
\hline $50.000-100.000$ & 49 & $3.380 .919,15$ \\
\hline $100.000-500.000$ & 69 & $15.069 .009,19$ \\
\hline$>500.000$ & 22 & $42.666 .743,50$ \\
\hline
\end{tabular}

Fonte: Elaborada pelos autores.

Assim como nos resultados apresentados anteriormente para rotas lineares, com intuito de comparar os resultados obtidos, foi elaborada a Tabela 6 com as mesmas classes de distâncias da Tabela 5 e o mapa da classificação dos municípios de acordo com as distâncias totais percorridas pelas vias de transporte representados na Figura 4.

Tabela 6 - Distâncias percorridas pelos veículos de RSU através de rotas por vias

\begin{tabular}{c|c|c}
\hline \multicolumn{3}{c}{ Rotas por Vias } \\
\hline $\begin{array}{c}\text { Distância Percorrida } \\
\text { (Ida/Volta) x no de viagens (km) }\end{array}$ & $\mathbf{N}^{\circ}$ de Municípios & $\begin{array}{c}\text { Distância Total } \\
(\mathbf{k m})\end{array}$ \\
\hline$<1.000$ & 149 & $71.820,25$ \\
\hline $1.000-50.000$ & 322 & $3.587 .535,25$ \\
\hline $50.000-100.000$ & 48 & $3.422 .717,16$ \\
\hline $100.000-500.000$ & 89 & $19.410 .524,92$ \\
\hline$>500.000$ & 36 & $65.437 .556,31$ \\
\hline
\end{tabular}

Fonte: Elaborada pelos autores. 
A análise da Tabela 6 mostra que a quantidade de municípios que compõem cada uma das classes é proporcional ao das rotas lineares. O intervalo de 1.000 a $50.000 \mathrm{~km}$, contém o maior número de municípios, aproximadamente 50\% fazem parte dessa classe e o segundo intervalo que abrange mais municípios continuou sendo o de distâncias inferiores a 1.000 $\mathrm{km}$, com aproximadamente $23 \%$ dos municípios. Os outros municípios estão distribuídos nas classes de 50.000 a $100.000 \mathrm{~km}$ e 100.000 a $500.000 \mathrm{~km}$, representando cerca de $8 \%$ e $14 \%$ do total.

Vale ressaltar que o número de municípios que realizaram um percurso de mais de $500.000 \mathrm{~km}$ aumentou de 22 nas rotas lineares para 36 nas rotas por vias de transporte, em decorrência disso o valor da distância total subiu em torno de 53\%. Esse aumento está relacionado a metodologia adotada e era esperado que as distâncias por vias fossem maiores que as distâncias lineares, uma vez que as estradas normalmente não possuem as distâncias mais curtas entres os centros urbanos e os aterros e geralmente são construídas levando em consideração aspectos geomorfológicos e outros obstáculos naturais. 
Figura 4 - Classificação dos municípios do estado de São Paulo de acordo com as distâncias

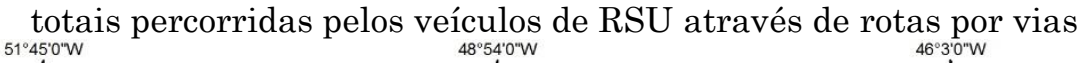

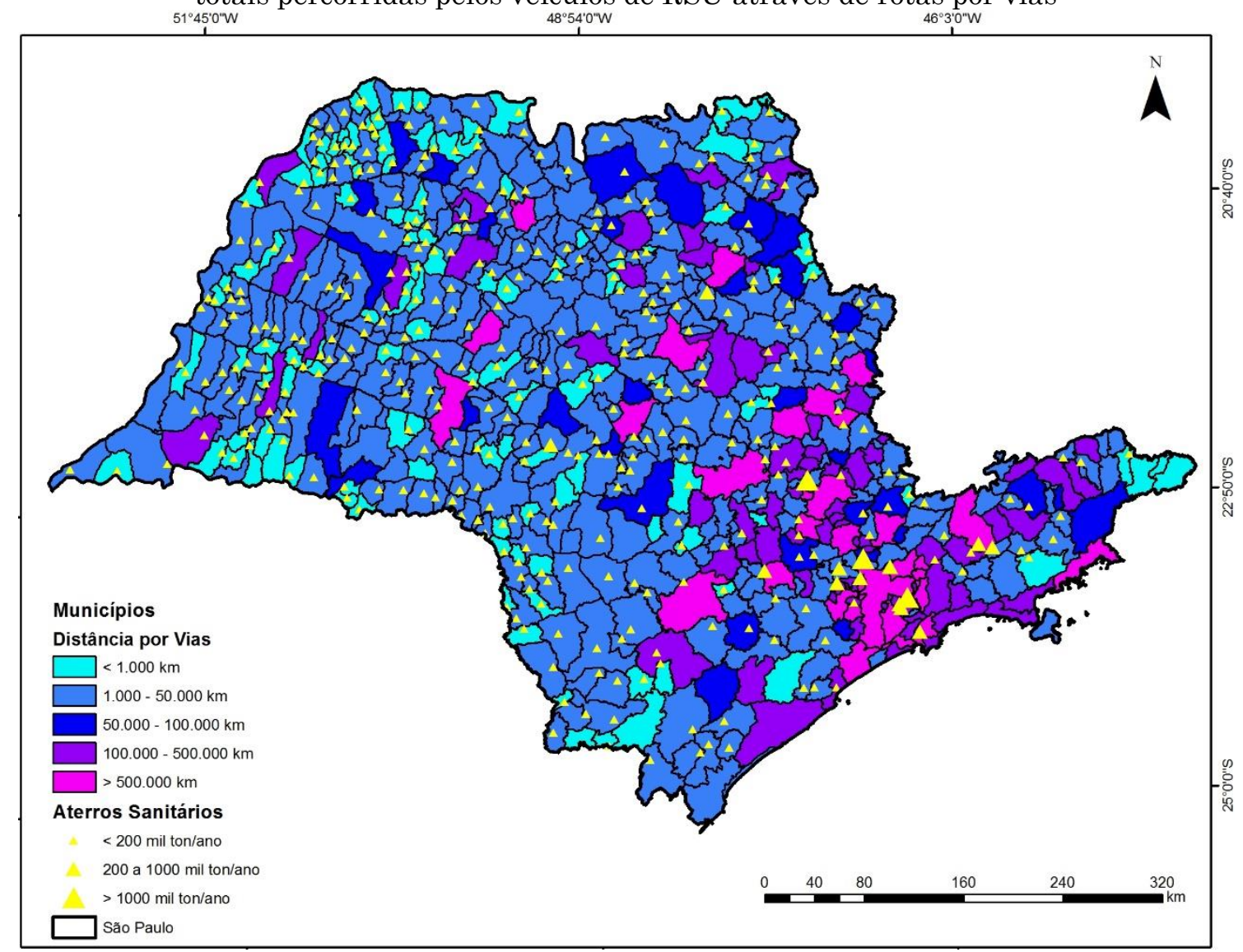

Fonte: Elaborada pelos autores.

$\mathrm{Na}$ Figura 4 é possível visualizar os municípios de acordo com o intervalo de distâncias percorrido para dispor os seus resíduos sólidos por vias de transporte e levando em consideração o número de viagens necessárias para se dispor os RSU. É possível identificar no mapa que os municípios que percorrem as maiores distâncias, demarcados na cor magenta, não possuem aterros sanitários no seu território e estão localizados principalmente na Macrometrópole Paulista, que envolve as Regiões Metropolitanas de São Paulo, Baixada Santista, Campinas, Sorocaba e do Vale do Paraíba e Litoral Norte, além das Aglomerações Urbanas de Jundiaí e de Piracicaba. 


\section{Conclusão}

As taxas de crescimento da geração dos RSU tendem aumentar no Brasil tanto em valores per capita como em valores totais, uma vez que a população também tende a crescer. Ainda que a busca pela diminuição na geração dos RSU se encontre na PNRS o cenário brasileiro confronta esta realidade uma vez que a geração de RSU vem aumentando acentuadamente.

No que tange ao volume de resíduo gerado, quanto maior for este número mais eficiente deve ser a gestão. Entre outros fatores, um gerenciamento inadequado pode implicar no esgotamento dos aterros sanitários existentes dentro dos municípios e/ou nas proximidades, acarretando maiores distâncias para se dispor estes resíduos e também no aumento no número de viagens que os veículos coletores de RSU precisam realizar.

No ano de 2016 a quantidade total de RSU disposto nos 401 aterros utilizados entre os municípios do estado de São Paulo, foi de aproximadamente 14,6 milhões de toneladas. As distâncias dos centros urbanos até os locais de disposição final obtidos pelas rotas lineares e por vias de transporte foram em torno de $11.280 \mathrm{~km}$ e $17.641 \mathrm{~km}$, respectivamente.

Para obtenção da distância percorrida estimada, foi considerado nos cálculos, além do valor referente ao percurso de ida e volta, o número de viagens necessárias para que todo o resíduo gerado no município fosse disposto nos aterros. Neste contexto, vale salientar que aproximadamente $62 \%$ do total de municípios fizeram menos de 500 viagens para disporem seus resíduos, isso se justifica pelo fato de que $42 \%$ dos municípios paulistas possuem menos do que 10 mil habitantes e consequentemente não geram grandes quantidades de RSU.

A somatória dos resultados obtidos pelas rotas por vias de transporte, considerando o percurso de ida e volta e o número de viagens, mostra que para 2016 foram percorridos pelos veículos coletores de RSU cerca de 91.913.928 $\mathrm{km}$. Como comparação, este valor estimado seria suficiente para dar mais de 
2.293 voltas no planeta Terra pela linha do Equador que é o percurso mais distante para dar a volta no globo terrestre.

Estes cerca de 91 milhões de quilômetros percorridos, além de ocasionarem um significativo custo econômico contribuem com elevado potencial de poluição ambiental e impactos negativos à saúde, principalmente ao que se refere a emissão de poluentes e de gases de efeito estufa, agravadores do aquecimento global o que se sugere analisar em estudos futuros.

\section{Agradecimentos}

Os autores gostariam de agradecer a bolsa de Iniciação Cientifica PIBIC/INPE/CNPq Processo n ${ }^{0}$ 170752/2017-8 da autora Laryssa Alvarenga de Morais e a bolsa de Pós-doutorado PNPD/CAPES Processo $n^{0}$ 88882.316284/2019-01 do autor Victor Fernandez Nascimento. Além disso, gostaríamos de agradecer ao INPE, UFGRS e ao Campus da Unesp de São José dos Campos, instituições dos autores deste artigo.

\section{Contribuição dos autores}

Os autores VFN e JPHBO tiveram a ideia do projeto, a autora LAM coletou os dados e realizou os cálculos das rotas e as estimativas das distâncias, além de escrever o artigo junto com o autor VFN, o qual elaborou os produtos cartográficos e respondeu aos comentários e sugestões dos revisores, por último, os autores JPHBO e LAG revisaram o trabalho. 


\section{Referências}

ABRELPE, Associação Brasileira de Limpeza Pública e Resíduos Especiais. Panorama dos Resíduos Sólidos no Brasil 2016. Site $<$ http://www.abrelpe.org.br/Panorama/panorama2016.pdf>, acessado em abril de 2019.

ABRELPE, Associação Brasileira de Limpeza Pública e Resíduos Especiais. Panorama dos Resíduos Sólidos no Brasil 2017. Site $<$ https://belasites.com.br/clientes/abrelpe/site/wpcontent/uploads/2018/09/SITE_grappa_panoramaAbrelpe_ago_v4.pdf>, acessado em abril de 2019.

ASSOCIAÇÃO BRASILEIRA DE NORMAS TÉCNICAS (ABNT). NBR 13463: Coleta de resíduos sólidos. Rio de Janeiro, 1995. 5-7p.

BRASIL. Lei $\mathrm{n}^{\mathrm{o}}$ 12.305, de 2 de agosto de 2010. Institui a Política Nacional de Resíduos Sólidos; e dá outras providências. Diário Oficial da União. Brasília, 3 ago. 2010.

CETESB, Companhia Ambiental do Estado de São Paulo. Inventário Estadual de Resíduos Sólidos Urbanos. Relatório Técnico, São Paulo, 2012. 118p.

CETESB, Companhia Ambiental do Estado de São Paulo. Inventário Estadual de Resíduos Sólidos Urbanos. Relatório Técnico, São Paulo, 2016. 122p.

CETESB, Companhia Ambiental do Estado de São Paulo. Inventário Estadual de Resíduos Sólidos Urbanos. Relatório Técnico, São Paulo, 2017. 120p.

CHANG, N. B.; LU, H. Y.; WEI, Y. L. GIS technology for vehicle routing and scheduling in solid waste collection systems. Journal of environmental engineering, v. 123, n. 9, 1997. p. 901-910.

ANDRADE, R. M. D.; FERREIRA, J. A. A gestão de resíduos sólidos urbanos no Brasil frente às questões da globalização. Rede-Revista Eletrônica do PRODEMA, v. 6, n. 1, 2011.

DEAR, M. Understanding and Overcoming the NIMBY Syndrome. Journal of the American Planning Association, v. 58, n. 3, 2007. p. 288-300.

GALlARDO, A.; CARLOS, M.; PERIS, M; COLOMER, F. J. Methodology to design a municipal solid waste pre-collection system. A case study. Waste management, v. 36, 2015. p. 1-11. 
GODECKE, M. V.; NAIME, R. H.; FIGUEIREDO, J. A. S. O consumismo e a geração de resíduos sólidos urbanos no Brasil. Revista Eletrônica em gestão, educação e tecnologia ambiental, v. 8, n. 8, 2012. p. 1700-1712.

GONZÁLEZ, G. A. A.; LEAL, J. E. Planejamento das Rotas de Coleta de Resíduos Sólidos Domiciliares Especiais por meio de um Sistema de Informações Geográficas para Transporte: Aplicação do Algoritmo do Problema de Roteirização dos Veículos com Janela de Tempo. Blucher Marine Engineering Proceedings, v. 2, n. 1, 2016. p. 484-494.

GOUVEIA, N. Resíduos sólidos urbanos: impactos socioambientais e perspectiva de manejo sustentável com inclusão social. Ciência \& Saúde Coletiva, v. 17, n. 6, 2012. p. 1503-1510.

IBGE, Instituto Brasileiro de Geografia. Pesquisa Nacional de Saneamento Básico 2008. IBGE, Rio de Janeiro, 2010. 219 p.

MALAKAHMAD, A.; BAKRI, P. M.; MOKHTAR, M. R. M.; KHALIL, N. Solid waste collection routes optimization via GIS techniques in Ipoh city, Malaysia. Procedia Engineering, v. 77, 2014. pp. 20-27.

MARTINHO, M. G. M.; GONÇALVES, M. G. P. Gestão de resíduos. Lisboa: Universidade Aberta, 2000. 281 p.

MOUSTAFA, A.; BAKRI, P. M.; MOKHTAR, M. R. M.; KHALIL, N. Waste collection vehicle routing problem: case study in Alexandria, Egypt. In: The 19th International Conference on Industrial Engineering and Engineering Management. Springer, Berlin, Heidelberg, 2013. p. 935-944.

NASCIMENTO, V. F.; SOBRAL, A. C.; FEHR, M.; YESILLER, N.; ANDRADE, P. R.; OMETTO, J. P. H. B. Municipal solid waste disposal in Brazil: improvements and challenges. International Journal of Environment and Waste Management, v. 23, n. 3, 2019. p. 300-318.

SPIGOLON, L. M. G. A otimização da rede de transporte de RSU baseada no uso do SIG e análise de decisão multicritério para a localização de aterros sanitários. Tese de Doutoramento. Universidade de São Paulo. Programa de Pós-graduação em Engenharia de Transporte, São Carlos, 2015. $217 \mathrm{p}$. 
TAVARES, G.; ZSIGRAIOVA, Z.; SEMIAO, V.; CARVALHO, M. D. G. Optimisation of MSW collection routes for minimum fuel consumption using 3D GIS modelling. Waste Management, v. 29, n. 3, 2009. p. 1176-1185.

VILHENA, A. Lixo municipal: manual de gerenciamento integrado. (Instituto de Pesquisas Tecnológicas (IPT) - Compromisso Empresarial para Reciclagem (CEMPRE). 3. Ed. São Paulo, 2010.

WWF, World Wide Fund for nature. Relatório Planeta Vivo 2010. Out. 2010. Site <wwf.org.br/informacoes/bliblioteca/?26162/Relatrio-Planeta-Vivo-2010>, acessado em abril de 2019.

ZVEIBIL, V. Z. Manual de gerenciamento integrado de resíduos sólidos. Relatório Técnico, Instituto Brasileiro de Administração Municipal (IBAM), Curitiba, 2001. 204p. 